\title{
A Assistência Social e seus Aspectos Perante o Estatuto da Pessoa com Deficiência e sua Inclusão Social
}

\section{Social Assistance and its Aspects in the Status of People with Disabilities and Their Social Inclusion}

\author{
Franciele Maria Andrade ${ }^{\mathrm{a}}$; Fabiola Cristina Carrero Taques*a
}

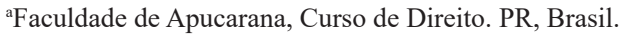

*E-mail: fabiolacarrero@gmail.com

\begin{abstract}
Resumo
Este estudo tem como objetivo principal analisar a luta de uma sociedade onde todos possam usufruir de oportunidades iguais, destacando-se o grupo das pessoas com deficiência, que trabalham todos os dias para assegurar que seus direitos sejam cumpridos. Quebrando barreiras que as pessoas têm em relação à deficiência, demandando uma atividade disciplinada em busca de circunstâncias políticas e legais, vantajosas à inclusão. Buscou-se por pesquisa bibliográfica, a fim de compreender qual o posicionamento doutrinário e jurisprudencial desta matéria, pois há muitos questionamentos referentes ao assunto, nos quais iremos abordar os impactos dessas pessoas titularizadas de deficientes, que também são detentores de direitos, pois gozam de capacidade legal em igualdade de condições com as demais pessoas em todos os aspectos da vida.

Palavras-chave: Deficiência. Igualdade. Inclusão Social.
\end{abstract}

\begin{abstract}
This study `s main objective is to analyze the fight of a society where every individual may enjoy equal opportunities, highlighting the group of people with disabilities, who work every day to assure its rights are fulfilled. Breaking barriers that people have towards disabilities, demanding a disciplined activity in search of political and legal circumstances, that are advantageous to inclusion. Sought through bibliographic research, to understand what is the doctrinal and jurisprudential position of this subject, for there are many inquiries referring to the topic, where will be approached the impacts of these people labeled as disabled, that are also right holders, because they have legal capacity in equal conditions as other people in all aspects of life.
\end{abstract}

Keywords: Deficiency. Equality. Social Inclusion.

\section{Introdução}

O estudo teve por finalidade verificar os aspectos relacionados à seguridade social e também a saúde, previdência, com ênfase na assistência social e também sobre como o estatuto da pessoa com deficiência é relevante, pois se trata de direitos há pessoas que necessitam cada dia mais de atenção, respeito e mudanças de uma sociedade enraizada em seus próprios conceitos.

Sendo um direito essencial à pessoa, a seguridade social foi comtemplado na Constituição Federal de 1988 no capítulo II do título VIII, "Da Seguridade Social”, no artigo 194 e seus incisos, do texto constitucional. (BRASIL, 1988)

Em 04 de Janeiro de 2016, entrou em vigor a Lei Nacional $\mathrm{n}^{\mathrm{o}} 13.146$ de 06 de julho de 2015, chamado de Estatuto da Pessoa com Deficiência. A chegada dessa lei representa um grande avanço em relação á proteção da pessoa com deficiência e sua inclusão em sociedade.

Analisando também os requisitos para concessão do benefício assistencial se tratando das pessoas com deficiência, como também a constituição federal e seus aspectos perante a assistência social.

E relatando um estudo diante da efetivação da Lei brasileira de inclusão da pessoa com deficiência, também chamada de estatuto da pessoa com deficiência, onde abordaremos vários critérios e mudanças sobre o assunto. Analisando temas sobre seguridade social, abrangendo, saúde, previdência social e assistência social, estudando seus conceitos e requisitos.

O tema também trata dos direitos fundamentais das pessoas com deficiência, como educação, transporte e saúde e também sobre a inclusão deles na sociedade.

Primeiramente será feito um breve contexto da seguridade social, a importância da assistência social para os indivíduos que necessitam de atendimento e amparo da sociedade, a importância da saúde, pois é considerado um dos serviços públicos mais importantes concernentes às pessoas. $\mathrm{O}$ amparo assistencial á pessoas que necessitam de atendimento especial em sociedade, mostrando seus requisitos e garantias.

Sendo abordados principais princípios que norteiam a garantia de direitos dessas pessoas titularizadas de deficientes, seguindo para um breve histórico das pessoas com deficiência e de como o seu caminho foi percorrido até os tempos de hoje, acompanhando a definição de pessoa com deficiência.

E por fim abordando assuntos perante o estatuto da pessoa com deficiência e sua inclusão social, fazendo valer os direitos e garantias de todas essas pessoas que necessitam de atenção 
maior de uma sociedade ainda enraizada e atrasada em avanços que possam facilitar e promover uma inclusão justa e necessária em sociedade.

Desta forma o objetivo desse estudo foi abordar a assistência social e como ela funciona em sociedade, quais suas vantagens em relação aos mais necessitados, abordando principalmente a questão do deficiente físico, seus direitos e garantias, e o dever do Estado em garantir esses direitos. Analisando o mecanismo da Lei $n^{\circ} 13.146$ de 6 de julho de 2015, institui a Lei Brasileira de Inclusão da Pessoa com Deficiência também chamada de Estatuto da Pessoa com Deficiência que foi criada para regulamentar os direitos das pessoas com deficiência, e garantindo a sua inserção em sociedade, tornando cada dia mais eficaz sua inclusão.

\section{Desenvolvimento}

\subsection{Metodologia}

Trata-se de uma revisão em relação a pessoa com deficiência física e seus direitos e garantias em sociedade. Utilizou bibliografia contendo jurisprudências e legislações. Para poder obter nortear a pesquisa foram utilizadas como palavras-chave: Assistência social, pessoa com deficiência e inclusão social.

\subsection{Discussão}

A Assistência Social é assegurada na Constituição Federal de 1988 nos artigos 203 e 204 e também prevista na Lei ${ }^{\circ}$ 8.742 de 7 de Dezembro de 1993, denominada Lei Orgânica da Assistência Social, com função de prestar auxílio a todos aqueles que necessitam, especialmente os idosos e deficientes.

$\mathrm{Na}$ Carta Magna no artigo $5^{\circ}$, todos são iguais perante a lei, sem distinção de qualquer natureza, garantindose aos brasileiros e aos estrangeiros residentes no País a inviolabilidade do direito à vida, à liberdade, à igualdade, à segurança e à propriedade (BRASIL, 1988).

Em relação à Assistência Social, Vianna (2008) menciona sendo, política social que provê o atendimento das necessidades básicas, a assistência social traduz-se a assistência social em ações e benefícios que objetivam a proteção à família, à maternidade, à infância, à adolescência, à velhice e à pessoa com deficiência, independentemente de qualquer contribuição ao sistema da Seguridade Social.

De acordo com Balera e Mussi (2015) a seguridade social, abarca todo aquele que, não tendo capacidade econômica para contribuir, necessite de amparo de tal sistema e não esteja enquadrado no rol de segurados obrigatórios da Previdência Social. Por isso, a Assistência Social toma como objetivo a proteção do nascimento à morte da pessoa, buscando incluir socialmente todos aqueles que se encontram à margem da sociedade.

No entanto para Santos (2016) a assistência Social não é, na verdade, meramente assistencialista, porque não se destina apenas a dar socorro provisório e momentâneo ao necessitado. O que pretende a Constituição é que a Assistência Social seja um fator de transformação social. Deve promover a integração e a inclusão do assistido na vida comunitária, fazer com que, a partir do recebimento das prestações assistenciais, seja "menos desigual" e possa exercer atividades que lhe garantam a subsistência.

Afinal, pode-se compreender que a assistência social visa também a integração do indivíduo em situação de vulnerabilidade ao convívio em sociedade, garantindo-lhe melhores condições para viver em harmonia e igualar sua situação social com os demais, mas por sua vez o indivíduo deve provar sua necessidade de requerer os benefícios da assistência social.

A Lei $n^{\circ}$ 8.742/93 - Lei Orgânica da Assistência Social em seus art. $1^{\circ}$ e $2^{\circ}$ e respectivos incisos ${ }^{1}$, traz as definições e objetivos a respeito do cidadão perante a assistência social e os direitos a eles reunidos. Tem como função prestar auxílio a quem dela necessitar, em especial os idosos e deficientes. Segundo Torres (2018), a Lei foi criada para recolher o cidadão que não possui condições de suprir suas necessidades básicas em sociedade, tirar de situações precárias e reintegrálo á uma vida mais digna.

Sabendo que a seguridade social, saúde, previdência e assistência social garantem direitos aos mais necessitados, será analisado ao longo do exposto trabalho os direitos concernentes ao portador de deficiência e como evoluiu o seu conceito ao passar dos anos e também suas dificuldades perante a inclusão em sociedade.

O Censo Demográfico realizado em 2010 pelo Instituto Brasileiro de Geografia e Estatística (IBGE, 2010) apresentou que mais de 45 milhões de pessoas declararam ter pelo menos uma das deficiências investigadas (visual, auditiva, mental e motora), representando $23,9 \%$ da população brasileira. É de se considerar um percentual significante, e merece toda

1 Art. $1^{\circ}$ A assistência social, direito do cidadão e dever do Estado, é Política de Seguridade Social não contributiva, que provê os mínimos sociais, realizada através de um conjunto integrado de ações de iniciativa pública e da sociedade, para garantir o atendimento às necessidades básicas. Art. 2o A assistência social tem por objetivos: I - a proteção social, que visa à garantia da vida, à redução de danos e à prevenção da incidência de riscos, especialmente: a) a proteção à família, à maternidade, à infância, à adolescência e à velhice; b) o amparo às crianças e aos adolescentes carentes; c) a promoção da integração ao mercado de trabalho; d) a habilitação e reabilitação das pessoas com deficiência e a promoção de sua integração à vida comunitária; e e) a garantia de 1 (um) salário-mínimo de benefício mensal à pessoa com deficiência e ao idoso que comprovem não possuir meios de prover a própria manutenção ou de tê-la provida por sua família; II - a vigilância socioassistencial, que visa a analisar territorialmente a capacidade protetiva das famílias e nela a ocorrência de vulnerabilidades, de ameaças, de vitimizações e danos; III - a defesa de direitos, que visa a garantir o pleno acesso aos direitos no conjunto das provisões socioassistenciais. Parágrafo único. Para o enfrentamento da pobreza, a assistência social realizase de forma integrada às políticas setoriais, garantindo mínimos sociais e provimento de condições para atender contingências sociais e promovendo a universalização dos direitos sociais. 
atenção e amparo para as pessoas que apresentam algum tipo de deficiência.

De acordo com Pacheco e Alves (2007), a marginalização da pessoa com deficiência sempre existiu e possuíam a ideia de que a deficiência adivinha de espíritos maus, como forma de castigos, ligados a coisas ruins a miséria e sujeira, e o destino de muitos era viverem jogados e abandonados nas ruas sem nenhum tipo de amparo e com olhares de reprovação.

Ao passar dos anos, alguns conceitos e culturas mudaram, trazendo uma nova visão em relação aos deficientes, não se esquecendo de que foi um processo lento, pois diariamente nos deparamos com situações de preconceitos por parte de pessoas que não sabem lidar com a situação.

Atualmente a busca pela aceitação e reintegração da pessoa com deficiência se torna cada vez mais importante para ter uma sociedade sem preconceitos e igualitária, surge a cada dia amparos como casas, hospitais, avanços na medicina, saúde, educação, mercado de trabalho, transporte, lazer e leis que garantem os direitos e acessibilidade a essas pessoas, igualando seu cotidiano com os demais.

Para entender de forma simples o significado de deficiente o dicionário online de português nos traz o seguinte conceito, deficiente é: quem possui algum tipo de deficiência, funcionamento ausente ou insuficiente de um órgão. Pessoa cujas faculdades físicas ou intelectuais são diminuídas em comparação ao seu funcionamento esperado. Para melhor entendimento, Baptista e Tardivo (2008) afirmam que deficiência é qualquer perda, falta ou alteração de estrutura ou função, qualquer que seja sua causa.

De acordo com Marques (2013), a deficiência não é apenas a falta de sentido, função, total ou parcial, e sim a carência de ações por parte da sociedade para compensar eventual falta ou lacuna, oportunizando a inclusão dessa pessoa, em condições de igualdade, com os demais cidadãos. Segundo Araujo (1997) a deficiência, há de ser entendida levando-se em conta o grau de dificuldade para a inclusão social e não apenas a constatação de uma falha sensorial ou motora, por exemplo.

A Lei $n^{\circ} 13.146$ de 6 de julho de 2015 institui a Lei Brasileira de Inclusão da Pessoa com Deficiência, chamada de Estatuto da Pessoa com Deficiência, criada para regulamentar a Convenção da ONU sobre os direitos das pessoas com deficiência que resguardam os direitos iguais. Godoy (2016) acentua que a lei é ampla e aborda vários pontos do cotidiano das pessoas com deficiência e significativo avanço para a sociedade brasileira no caminhar para a verdadeira e efetiva inclusão. $\mathrm{O}$ art. $3^{\circ}$ demonstra os apoios especiais, ajudas técnicas e procedimentos especiais necessários para facilitar a inclusão e autonomia na sociedade. Determina o art. 10 que: "Compete ao Poder público garantir a dignidade da pessoa com deficiência ao longo de toda a sua vida". O art. 53 dispõe sobre a acessibilidade, "direito que garante à pessoa com deficiência ou com mobilidade reduzida viver de forma independente e exercer seus direitos de cidadania e de participação social". Portanto a Lei abrange maiores conceitos e aborda critérios com mais flexibilidade, e traz consigo a importância de a pessoa com deficiência ser incluída de forma igualitária.

Sabe-se que a inclusão da pessoa com deficiência tem apresentado avanços, mas com falhas que precisam ser ajustadas. Conforme Silva (2017) a inclusão como movimento social, político e educacional, é sem dúvida, um dos maiores desafios, desde a década de 70. Ela assiste e defende o direito que todo o cidadão possui de ir e vir na sociedade.

A mudança de comportamento da sociedade é fundamental para inclusão. Sabe-se que nos dias atuais pessoas têm trabalhado para criar novas garantias e direitos e principalmente fazer valer as leis já existentes, em busca de proporcionar mais segurança aos que precisam de atendimento diferenciado.

A inclusão é um processo e pode ser modificado conforme novas descobertas e necessidades. Pois a sociedade ainda se fecha para o que é diferente e desconhecido. De acordo com Gil (2017) afirmar que a inclusão é um processo, significa dizer que ela muda à medida que avança, encontra dificuldades e pode dar passos para trás até descobrir outros caminhos a partir da interação com pessoas, fatos e circunstâncias de cada tempo e momento. Significa também dizer que ela nasce dentro de cada um de nós, mesmo naqueles que já se consideram "inclusivos". Sempre temos algo a aprender. Há sempre mais uma fronteira para transpor.

Deve-se levar em questão, se os meios utilizados para inclusão estão sendo eficazes e garantindo os direitos, se estão sendo feitos e mantidos de forma correta. Verificando novos projetos e ações que promovam cada dia.

A assistência social surgiu com a finalidade de dar garantia aos mais necessitados, que precisam de uma certa atenção perante a sociedade, como os idosos e deficientes, criou benefícios com intenção de ajudar essas pessoas desamparadas e muitas vezes esquecidas em relação aos seus direitos. Analisando os princípios que regem a assistência social é possível verificar que cada um busca dar garantia de o mínimo de dignidade há qualquer pessoa em sociedade e principalmente aos deficientes.

Por esses motivos, a questão do "assistencialismo" e inclusão da pessoa deficiência precisa ser discutida com cuidados, criando possibilidades para seu convívio em sociedade. Ainda há preconceitos que dificultam sua integração, portanto, não cabe só ao Estado garantir os direitos desses indivíduos, mas também de toda a sociedade.

\section{Conclusão}

A Assistência social e os benefícios assistenciais são normalmente abordados de forma resumida pela doutrina, apenas com referências a constituição e a lei no 8.742/1993. Existem várias discussões que envolvem a previdência social e a assistência social e o benefício de prestação continuada, trazendo diversas controvérsias.

O benefício assistencial se torna importante para que indivíduos idosos ou deficientes, muitas vezes abandonados 
pela sua família, e também pelo Estado, fornecendo um suporte para sua subsistência.

A seguridade social e a assistência social tem papel fundamental para garantir a segurança dos indivíduos que necessitam, seja idoso ou deficiente, possibilitando melhores condições de vida.

Deve-se destacar a importância desse direito, pois essas pessoas muitas vezes se encontram em situações de vulnerabilidade, com menores chances no mercado de trabalho, educação, saúde, transportes e o preconceito, entre outras situações do cotidiano de um indivíduo que vive em sociedade, gerando assim a desigualdade e não promovendo sua inclusão.

A história percorrida pela pessoa com deficiência ao longo do tempo pode-se ver o lento processo a ser percorrido para a busca de respeito, igualdade e inclusão na sociedade. A lei no 13.146/2015, o Estatuto da Pessoa com Deficiência, conhecido como Lei de Inclusão, apresentaram garantias. Contudo, respeitar a pessoa com deficiência é ter uma série de cuidados para que não sejam excluídos do nosso convívio do dia- a- dia, é nosso dever respeita-los, cabendo ao Estado criar mecanismos de inserção dessas pessoas na sociedade, criando recursos personalizados para desenvolver seu potencial e vencer seus obstáculos.

\section{Referências}

ARAUJO, L.A.D. A proteção constitucional das pessoas portadoras de deficiência. Brasília: Coordenadoria Nacional para Integração da Pessoa Portadora de Deficiência, 1997.

BALERA, W.; MUSSI, C.M. Direito previdenciário. São Paulo: Método, 2015.

BRASIL. Constituição Federal de 1988. Promulgada em 5 de outubro de 1988. Disponível em: http://www.planalto.gov.br/ ccivil_03/constituicao/constituicao.htm. Acesso em: 16 out.
2018.

COELHO, L. A inclusão social do deficiente físico em questão no Brasil. 2017. Disponível em: https://descomplica.com.br/blog/ redacao/modelo-de-redacao-a-inclusao-social-do-deficientefisico-em-questao-no-brasil/. Acesso em: 28 set. 2018.

DEFICIENTE. Dicio Dicionário Online de Português. Disponível em: https://www.dicio.com.br/deficiente/. Acesso em: 5 jul. 2019.

GIL, M. Quais são os desafios para a inclusão da pessoa com deficiência? Instituto Rodrigo Mendes. 2017. Disponível em: http://diversa.org.br/artigos/quais-sao-desafios-inclusao-pessoadeficiencia/. Acesso em: 19 ago. 2018.

GODOY, L. O novo Estatuto da Pessoa com Deficiência. 2016. Disponível em: https://www.jota.info/opiniao-e-analise/ colunas/luciano-godoy/o-novo-estatuto-da-pessoa-comdeficiencia-21122015. Acesso em: 9 jul. 2019.

IBGE - Instituto Brasileiro de Geografia e Estatística. Disponível em: https://biblioteca.ibge.gov.br/visualizacao/periodicos/94/ cd_2010_religiao_deficiencia.pdf. Acesso em: 5 jul. 2019.

MARQUES, I.L. Direitos difusos e coletivos: idosos e portadores de deficiência. São Paulo: Saraiva, 2013.

PACHECO, K.M.B.; ALVES, V.L.R. A história da deficiência, da marginalização à inclusão social: uma mudança de paradigma. Tendências e Reflexões, v.14, n.4, p.243, 2007.

SANTOS, M.F. Direito previdenciário. Sinopses Jurídicas. São Paulo: Saraiva, 2016.

SILVA, G.A. A inclusão social sob a visão do deficiente. 2017. Disponível em: http://www.uniedu.sed.sc.gov.br/wp-content/ uploads/2017/10/TCC-Gisele-Alves-da-Silva.pdf. Acesso em: 18 ago, 2019.

TORRES, E. Lei Orgânica de Assistência Social - LOAS, forma administrativa e sua previsão legal. 2018. Disponível em: https:// jus.com.br/artigos/65550/lei-organica-de-assistencia-social-loasforma-administrativa-e-sua-previsao-legal. Acesso em: 28 jun. 2019.

VIANNA, C.S.V. Previdência social: custeio e benefícios. São Paulo: LTR, 2008. 